\title{
Category set in anagram solutions
}

\section{J. P. COzZOLINO, CALIFORNIA STATE COLLEGE AT LONG BEACH, Long Beach, California}

The purpose of the present experiment was to study category set in multiple solution anagram problems. A category set was established among words that would not ordinarily be related. The hypothesis was: solutions found for anagrams vary as a function of category set. Ten Ss were divided into two groups, five for each. Group A read a paragraph containing one possible set of solutions (category words) for the anagrams and then solved 10 anagrams. Group $B$ read a different paragraph which did not contain any possible solutions for the anagrams and then solved the same 10 anagrams as Group A. The mean frequencies for the category words were compared for the two groups. It was found that Group $A$ had a significantly higher number of category words than Group B. Reasons for the high amount of variability in frequencies for each category word and implications for future studies are discussed.

A major problem for the psychological investigator has been to account for the "direction of thought." When confronted with a problem an individual makes one attempt at a solution out of a great number of possibilities. If the attempt proves to be incorrect the individual makes other attempts, while still other possibilities do not occur at all.

Word problems have been used to investigate the "category set," which can be defined as a tendency to respond to words belonging to a particular category or class, and which can be measured by the speed or frequency with which a response occurs. It has been demonstrated (Maltzman \& Morrisett, 1952) that Ss solve anagrams made from a list of words belonging to a common class more rapidly than anagrams not belonging to a common class. Rees \& Israel (1935) measured the strength of category set by comparing the frequency with which Ss solved multiple solution anagrams in accordance with an established set.

Some investigators have suggested that the laws governing the solving of anagrams are similar to those for verbal recall. Safren (1962), in studying the operation of category sets, suggested that processes in the solving of word problems such as anagrams may be similar to those in verbal recall, for in both verbal recall and anagram solving, associative strength between words significantly determines Ss' productions. Lorge \& Solomon (1960) also found that past experience is one of the factors that influences problem solving.

These findings suggested to the present $E$ that the establishment of "artificial" category sets probably effects the solutions found for anagrams. An artificial category set was defined as a category set that is made of words that would not naturally be associated. The present study attempted to establish an artificial category set and measure its effects. Ss then solved multiple solution anagram problems. The hypothesis was: solutions found for anagrams vary as a function of category set. The dependent variable was defined as the frequency of eategory words found in the solutions made by Ss. The independent variable consisted of the presence or absence of a category set.

\section{METHOD}

Subjects. The Ss were 10 students in a Psychology class at California State College at Long Beach. Ss were randomly divided into two ecpual groups.

Apparatus. Three sheets of paper were used. One contained Paragraph A, another Paragraph B, and the third one contained the 10 anagrams

Procedure. Both groups read a passage and then solved 10 anagrams. Each anagram had more than one possible solution and the only difference between the groups was in the passige read.

In Condition A (Group A), Ss read a passage that contianed one possible set of solutions (category words) for the anagrams. In Condition B (Group B), Ss read a passige that did not contain any possible solutions for the anagrams.
When Ss entered the laboratory a sheet of paper containing a passage was on their desks. E then read the following instructions:

"In front of you is a sheet of paper with a passage, which you are to read. When everyone is through, I will give further instructions."

When the group was through, E collected the sheets of paper and passed out another one with 10 anagrams on it. E then read the following:

"This part of the experiment involves solving the 10 anagrams on the sheet of paper in front of you. You are to determine with the aid of paper and pencil what the original word is. Record your answer next to each anagram. Work as rapidly as you can, since you will be allowed 20 minutes to complete the task. Have you any questions? (Pause.) Begin."

The following is the list of anagrams and the category words contained in paragraph $\mathrm{A}$ :
a) astet - state
b) wto - two
c) efer - free
d) ader - read
e) tac - act
f) leim - mile
g) repa - rape
h) tohwr - worth
i) crae - race
j) aldegin - leading

\section{RESULTS}

Category words were defined as those solutions to the anagrams that can be found in Paragraph $A$. The mean frequency of category words was compared between Group A and Group B (Fig. 1). For Group $A$ the mean frequency was 7.4 and for Group $B$ it was 3.0. To test for significance a $t$ test was applied. A $t$ value of 2.6 and df of 8 were obtained. This $t$ value was found to be significant beyond the .05 level.

In Fig. 2 the frequency of each category word was compared between groups. The frequencies for Group $A$ and Group B, respectively, were: state-5,2; two- 5,4 ; free-4,0; read- 3,3 ; act $-3,2$; mile $-5,2$; rape- 5,0 ; worth $-3,1$; race $-4,0$; leading $-0,1$. It was found that, except for "read" and "leading," category words had a higher frequency in Group A than in Group B. \section{DISCUSSION}

Since frequency of category words was significantly higher for Group A than Group B, the hypothesis was supported. Upon examination of each individual category word, it was found that there was considerable variability in their frequencies. This is in agreement with Rees \& Israel (1935). It was interesting that "read" and "leading" were the only two category words that did not have a higher frequency for Group A. During the experiment it was noted that Ss spent most of their time solving the anagram "leading." The difficulty level of the anagram may have been a factor that led to the obtained results. Another factor which may have influenced the solutions for both "read" and "leading" is the

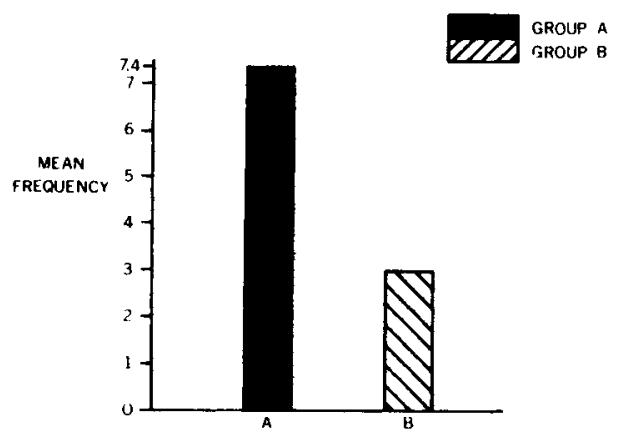

Fig. 1. Meaı frequency of category word wolutions. 


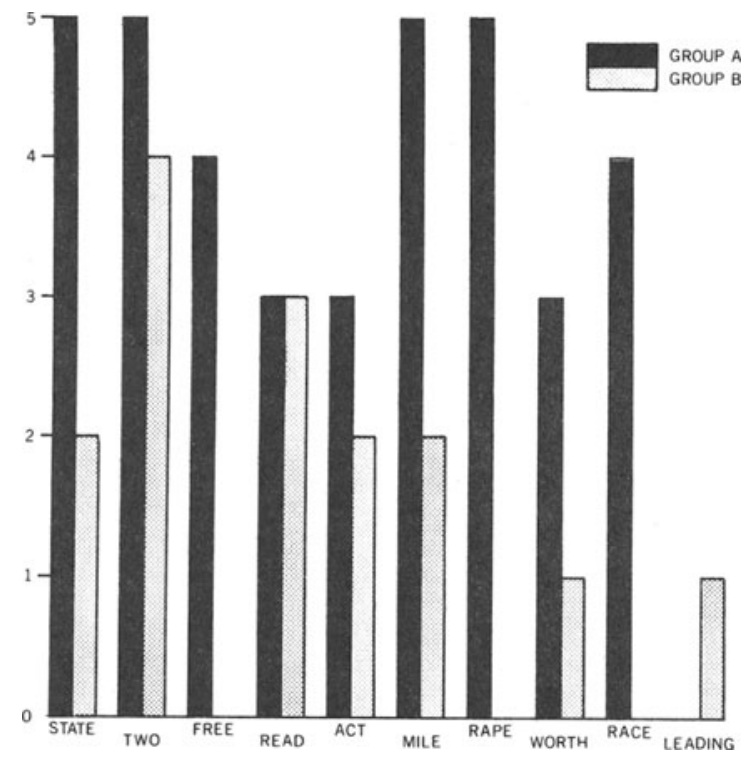

Fig. 2. Frequency of solutions for each category word. frequency of occurrence of each word. It has been shown (Mayzner \& Tresselt, 1958) that the variables of word frequency and difficulty level affect the solutions of anagrams.

There is not enough evidence from this study to say whether problem solving and verbal recall are governed by the same laws. The present study merely increases the probability that they are and also suggests that the difficulty level of a problem may effect these laws. Obviously, more research is needed to answer this question. But there is the implication in accordance with Safren (1962), that in future studies on the category set, stimulus materials should be calibrated by existing associative relationships for more precise predictions on the rate of problem solving.

\section{REFERENCES}

LORGE, I., \& SOLOMON, H. Group and individual performance in problem solving. Behav. Sci., 1960, 5, 28-38.

MALTZMAN, I., \& MORRISETT, L. Different strengths of set in the solution of anagrams. J. exp. Psychol., 1952, 44, 242-246.

MAYZNER, M., \& TRESSELT, M. Anagram solution times: A function of letter order and word frequency. J. exp. Psychol., 1958, 56, 376-379.

REES, H., \& ISRAEL, H. An investigation of the establishment and operation of mental sets. Psychol. Monogr., 1935, 46, No. 6 (Whole No. 210).

SAFREN, M. Association, sets, and the solution of word problems. J. exp. Psychol, 1962, 64, 40-45. 